\title{
Online Delivery of Electrical Engineering Courses Using the Online Flipped Classroom Approach
}

\section{Prof. John M. Santiago Jr, Colorado Technical University}

Professor John Santiago has been a technical engineer, manager, and executive with more than 26 years of leadership positions in technical program management, acquisition development and operation research support while in the United States Air Force. He currently has over 16 years of teaching experience at the university level and taught over 40 different graduate and undergraduate courses in electrical engineering, systems engineering, physics and mathematics. He has over 30 published papers and/or technical presentations while spearheading over 40 international scientific and engineering conferences/workshops as a steering committee member while assigned in Europe. Professor Santiago has experience in many engineering disciplines and missions including: control and modeling of large flexible space structures, communications system, electro-optics, high-energy lasers, missile seekers/sensors for precision guided munitions, image processing/recognition, information technologies, space, air and missile warning, missile defense, and homeland defense.

His interests includes: interactive multimedia for e-books, interactive video learning, and 3D/2D animation. Professor Santiago recently published a book entitled, "Circuit Analysis for Dummies" in 2013 after being discovered on YouTube. Professor Santiago received several teaching awards from the United States Air Force Academy and CTU. In 2015, he was awarded CTU's Faculty of the Year for Teaching Innovations. Professor Santiago has been a 12-time invited speaker in celebration of Asian-Pacific American Heritage Month giving multi-media presentations on leadership, diversity and opportunity at various military installations in Colorado and Wyoming.

\section{Dr. Jing Guo, Colorado Technical University}

Dr. Jing Guo is a Professor in Engineering Department at Colorado Technical University. She is the course director in circuits and electronics area. She taught variety of underrated and graduate courses including capstone design in Electrical and Computer Engineering area. 


\title{
Online Delivery of Electrical Engineering Courses Using the Online Flipped Classroom Approach
}

\author{
John Santiago, Jr., Ph.D. and Jing Guo, D.Eng. \\ Colorado Technical University (CTU), College of Engineering, Colorado Springs, CO
}

\section{Introduction}

The student body in the College of Engineering consists mostly of adult learners. These students work full-time, a majority coming from active-duty military and military veterans. The college successfully developed and implemented a program curriculum consisting of day and night classes in electrical engineering and computer engineering. These programs are designed for the working adult and are eleven weeks long. The curriculum program provides a flexible schedule allowing students to successfully complete an ABET-accredited degree in either BSEE or BSCE. However, engineering courses for obtaining an MSEE and MSCE degree are only offered in the evening.

The classes are usually 2-3 hours long meeting twice a week. In these face-to-face classrooms, the College of Engineering uses an active learning approach ${ }^{1-3}$ to encourage higher-levels of thinking. Short 5-15 minute presentations followed by student-centered problem-solving activities replaced long lectures.

To provide additional educational opportunity, the College of Engineering (CoE) initiated an exploration of online delivery of existing engineering courses during 2015. The CoE felt a strong commitment to maintain the student-centered focus, and active learning strategies that had been observed to support the non-traditional student. Like the active-learning approach, the flipped classroom approach also targets higher-levels of thinking.

The college embraced a flipped classroom approach for online content delivery starting in April 2015 for the undergraduate programs. One reason for adopting a flipped classroom approach concerns the amount of time during a synchronous session when students and instructor are online together. From this perspective, the four full-time faculty determined that there is little time to do lecture online based on the combined full-time experience of 60-plus years of face-toface teaching to adult students. In a synchronous session, more time is needed to address student questions on the multimedia content, readings, homework and lab experiments. The faculty also wanted to have students practice on problem solving techniques during the online session.

Another reason for adopting the flipped classroom is based on the authors' years of acquired experience in developing interactive and multimedia content suitable for e-books and online delivery. The online flipped classroom as a teaching pedagogy are later described in detail defined by three main ideas. The approach leverages a number of technologies to translate the traditional ground or face-to-face teaching philosophy to one suited for online classroom environment.

The engineering faculty decided to first develop a freshman-level course entitled, Introduction to Engineering (EE110), consisting of basic electronics and weekly lab assignments. The 
introductory courses attempts to prepare those students who will be entering either the electrical or computer engineering programs.

The College of Engineering recognized online lab assignments will be the challenging part of the program curriculum. This insight was verified and validated when the flipped classroom was implemented to mimic the online chat session. In this case, when students meet in the classroom, it simulates the online chat session in two areas: (1) one chat session is for addressing student questions on the multimedia content, readings, and homework problems; and (2) the other chat session is to address lab questions, observe their conduct during the labs remotely, and guide them to the troubleshooting process.

If the College of Engineering can effectively deliver the lab content from this first course to meet student outcomes, then the engineering faculty can expect the development of future electrical engineering courses involving lab activities to go much smoother.

As mentioned earlier, the full-time engineering faculty have a combined teaching experience of over 60 years but no experience in developing and delivering a complete engineering course fully online. Because the engineering faculty has its primary focus on teaching, the full-time instructor carries a typical workload of four courses per quarter. Consequently, each instructor has taught between thirty to forty different engineering courses including math and physics during their stretch at the College of Engineering. During the development of the introductory course in engineering, the instructors reduced their workload down to 2-3 classes for one year to focus on content creation and instructional delivery.

\section{Traditional Face-to-Face (Ground) Teaching Philosophy}

Based on the authors' experience, providing a one-hour lecture is inefficient, especially when it comes to the student body at the University. Most of the students are working adults with family and kids. They usually work during the whole day and come to school at night. A two or three hour lecture during the evening class will lead them in becoming disengage and in extreme cases, they fall asleep. It was found that short 5 to 15 minute lectures followed by short exercises completed by the students achieve better learning outcomes and a more engaging learning experience.

For example, one approach of instruction involves solving engineering problems in a number of analytical concepts, such as circuit analysis or signals and systems. In this context, the teaching approach involves the following steps:

- Step 1. Introduce an engineering topic for 5 minutes. Motivate why this topic is important and relevant...keeping it short and sweet. Show how information will benefit students or tell a relevant war story based on experience.

- Step 2. Solve and work out an example analytical problem. The activity usually takes 5 to 15 minutes depending on the complexity of the problem.

- Step 3. Have students struggle with another similar problem for 10-15 minutes, either individually or in pairs. 
- Step 4. Solve problem together (10-15 minutes). An instructor can have one of the students solve the problem on the whiteboard and appropriately guide the student to unravel the problem requesting feedback from other students as well.

- Step 5. Take a break for 5-15 minutes and repeat for the next hour.

The above approach is not set in stone. The instructor can adapt the delivery of the material while addressing any student questions or reinforcing concepts for the next hour. For example, an instructor may have a short lab or hands-on exercise using Matlab/Simulink or PSPICE to emphasize the concept taught during the first hour. The above pedagogy is consistent with past teaching philosophies ${ }^{1,2}$.

So how does one translate, the face-to-face teaching that proved successful in the past to one that is suitable for online delivery? One approach is to leverage available technologies to emulate the successful active and student-centered learning philosophy found in the traditional face-to-face classroom.

In the digital and internet marketing world, "Content is King." as written by Bill Gates in 1996. And with the flipped classroom approach, this is no exception. Engaging and interactive multimedia content is a key component of the online flipped classroom approach as defined by the College of Engineering and described later in the paper. This is especially true if a student decides to take an undergraduate degree that is delivered fully online for several years.

\section{Leveraging Past Experience on Multimedia Content Creation Before EE110}

Professor Santiago's initial interest was already focused on developing and experimenting with interactive and multimedia textbooks (or e-books) back in 2003, shortly after his retirement from the U.S. Air Force. In 2008, he created a YouTube channel, independent of the flipped classroom approach. YouTube analytics was used to assess the effectiveness of the videos in teaching abstract engineering concepts for online teaching. This activity was several years before CTU initiated its 2015 strategic plan to provide delivery of engineering courses online in 2016.

Professor Santiago investigated techniques to develop multimedia e-books consisting of videos and other media. The multimedia recordings included using engineering tools and interactive teaching platforms like Matlab/Simulink, Labview/Multisim, PhET and Algodoo. The author explored numerous internet marketing technologies that appear applicable for developing educational content and suitable for online delivery. The research efforts led to uploading of YouTube videos to test and assess its effectiveness. In addition, the author tested interactive features found on YouTube. The experimental efforts led to a published book ${ }^{3}$ in 2013, when the author was discovered by a literary agent on YouTube. This past experience with multimedia content proved valuable in guiding the engineering faculty for online delivery of engineering content that started in 2015.

Professor Santiago created experimental videos in several technical subjects, including: circuit analysis, differential equations, trigonometry and pre-algebra. Based on this experience, about one hour of videos per week are needed to explain and deliver the content for a technical course. 
Table 1 are some of experimental results of uploading approximately 300 videos in YouTube during the past nine years. The author initially wanted to see the effectiveness of using simple screen capture on a writing tablet to emulate the whiteboard teaching found in a traditional classroom. These initial efforts are in support of creating multimedia e-books. However, videos or other multimedia content is one major component of the flipped classroom approach. This is consistent with efficient e-learning based on the works of other authors as well. ${ }^{4,5}$

\begin{tabular}{|c|c|c|c|c|}
\hline Video Title/Link & $\begin{array}{c}\text { Date } \\
\text { Uploaded }\end{array}$ & $\begin{array}{l}\text { Number of } \\
\text { Views }\end{array}$ & Likes & Dislikes \\
\hline $\begin{array}{l}\text { 1. Signal Processing Tutorial: Discrete-Time Convolution } \\
\text { Examples (Inverse z-Transform) } \\
\text { https://www.youtube.com/watch?v=yzV3xW8YfzQ\&t=2s }\end{array}$ & 20 Apr 2008 & 29,654 & 66 & 2 \\
\hline $\begin{array}{l}\text { Matlab Examples - Review of Discrete Convolution } \\
\text { using Matlab } \\
\text { https://www.youtube.com/watch?v=bPAKMS6_FWg\& } \\
\underline{\mathrm{t}=8 \mathrm{~s}}\end{array}$ & $27 \mathrm{Feb} 2009$ & 41,306 & 63 & 5 \\
\hline $\begin{array}{l}\text { 3. z-Transform Tutorial: z-Transform and inverse z- } \\
\text { Transform Examples \& Functions } \\
\text { https://www.youtube.com/watch?v=71KN9UtRKsA\&t=25s }\end{array}$ & $\begin{array}{ll}5 \mathrm{Jul} & 2009\end{array}$ & 77,884 & 124 & 8 \\
\hline $\begin{array}{l}\text { Matlab Examples - Amplitude Demodulation } \\
\text { (synchronous detection) } \\
\text { https://www.youtube.com/watch?v=R inHfiOILk }\end{array}$ & 26 Jun 2008 & 58,294 & 64 & 1 \\
\hline $\begin{array}{l}\text { Operational Amplifier Tutorial - Basic Non-Inverting } \\
\text { Op Amp (Part 2) } \\
\text { https://www.youtube.com/watch?v=3nW4hZ-PHxo }\end{array}$ & 1 Mar 2009 & 105,491 & 272 & 5 \\
\hline $\begin{array}{l}\text { 6. Simulink / Matlab Video Tutorial and Example - Low } \\
\text { Pass Filter - Bode Plots (Part 1) } \\
\text { https://www.youtube.com/watch?v=oDqTg3gweuw }\end{array}$ & 3 Jul 2009 & 162,869 & 193 & 11 \\
\hline $\begin{array}{l}\text { 7. [Classification of Signals and Systems] Continuous- } \\
\text { Time Signal to Discrete-Time Signal } \\
\text { https://www.youtube.com/watch?v=8kYPalpEsoA }\end{array}$ & 27 Mar 2013 & 7628 & 23 & 2 \\
\hline $\begin{array}{l}\text { 8. Matlab Simulation of Double Sideband Amplitude } \\
\text { Modulation-Suppressed Carrier at Receiver (for } \\
\text { Introduction to Engineering Course, EE110) } \\
\text { https://www.youtube.com/watch?v=k2T19rcd9YA\&t=76s }\end{array}$ & 10 Sep 2015 & 1467 & 10 & 0 \\
\hline $\begin{array}{l}\text { 9. Matlab Simulation of Frequency Modulation and } \\
\text { Demodulation of an FM Transmitted Signal (for } \\
\text { Introduction to Engineering Course, EE110) } \\
\text { https://www.youtube.com/watch?v=rH53WZXDN6U\&t=4 } \\
\text { gs }\end{array}$ & 10 Sep 2015 & 2937 & 3 & 0 \\
\hline $\begin{array}{l}\text { 10. PhET Simulation: Voltage and Pressure Analogy (for } \\
\text { Introduction to Engineering Course, EE110) } \\
\text { https://www.youtube.com/watch?v=qlsNMgY0Mb4\&t=5s }\end{array}$ & 5 Sep 2016 & 156 & 2 & 0 \\
\hline
\end{tabular}

Table 1. Past Experience of Selected and Sample Videos Using Camtasia as of 12 Jan 2017.

To support the online delivery of engineering courses, the College of Engineering felt that students need extensive practice on solving numerous problems based on the traditional face-toface instruction and experience. In other words, there is very little or no time to provide lecturebased material when both instructor and students are online synchronously if meeting for two to four hours each week. Effective use of online sessions should be reserve to address student 
questions on solving homework problems, multimedia content or lab assignments. If time permits during the online sessions, additional problem solving methods are presented.

The author's experimental results from YouTube show that multimedia content can serve as one key component for online delivery of engineering instruction.

Grounded on the active-learning approach from the face-to-face teaching philosophy and the authors' experience with developing multimedia content, the College of Engineering adopted a flipped classroom approach. A key component is the development of multimedia content.

\section{College of Engineering Channel: STEM Videos for the Flipped Classroom}

When engineering students initially found out about the College of Engineering's preliminary offering of delivering technical courses online, most of their immediate responses goes something like this: "there is no way I'm going to take an engineering course online". But after explaining the online and flipped classroom approach described in this paper, most of their fears and concerns appear to subside and were less adamant on

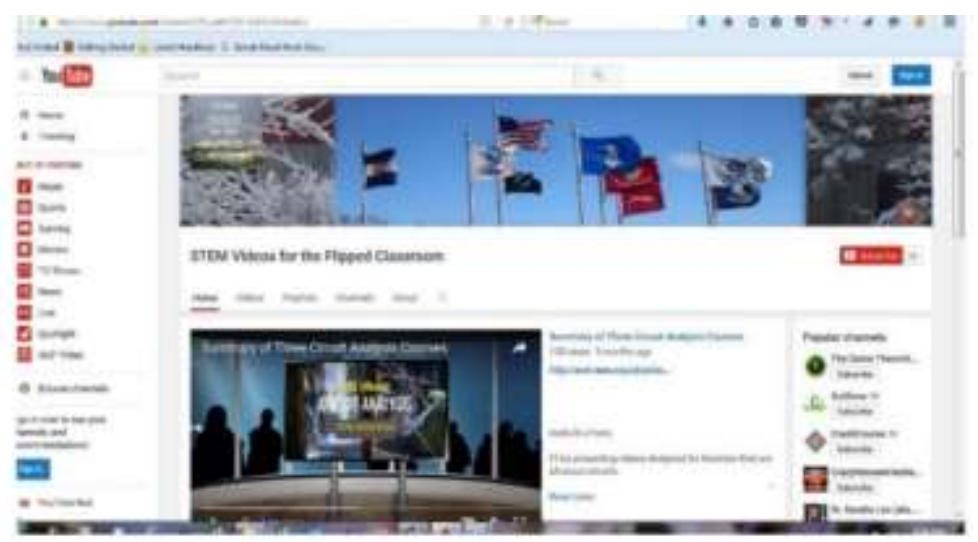

Figure 1. STEM Videos for the Flipped Classroom their position. As expected, some students remain skeptical since learning engineering is already a challenge in a traditional face-to-face classroom setting and are more comfortable with this instructional method. The students' reaction occurred during the first quarter of 2015. During 2016, Professor Guo taught three quarters of piloting the content and its delivery and refined the teaching approach. During 2016 Fall Quarter, interactive video was implemented and the student feedback was much more positive. However, some students do prefer the face-to-face approach as evidence from the survey results of outcomes, described later.

During 2015, the College of Engineering created a YouTube channel entitled, 'STEM Videos for the Flipped Classroom' in March and began developing multimedia content in July. Figure 1 is a screenshot of the College's channel. The channel serves as a repository of videos.

Table 2 provides a summary of highlevel analytics of selected and experimental YouTube Channels. Experimental Channels 1 and 2 are personal channels by one of the authors created in 2008-2009 and Channel 3 was created for the College of Engineering (STEM Videos for the Flipped Classroom) in 2015. In general, more videos with engaging content, results in more subscribers.

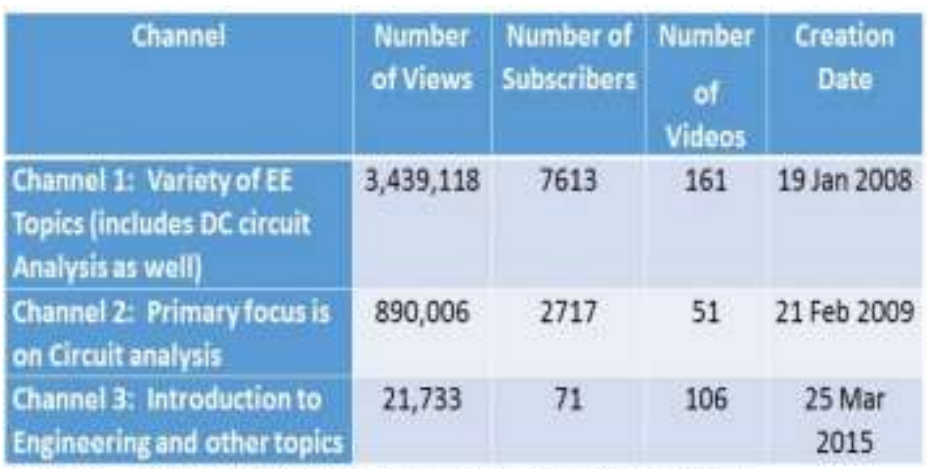

Table 2. Selected YouTube Channels as of 8 Jan 2017. 
Also, it takes time to build a subscriber list given today's increased competition. Channel 3 was created during March 2015, but initial postings of video content began in July 2015. CTU completed the final uploading of videos in March 2016 for the introductory course. However, additional videos were posted afterwards for continuous improvement on the online delivery of the course.

\section{Description of the Online Flipped Classroom Approach}

Figure 2 provides requirements and considerations for delivering online engineering content, the types of multimedia content and overview of implementing the online flipped classroom approach. In Figure 2, the block labeled 'Requirements and Considerations' highlights and summarizes are discussed elsewhere ${ }^{6,12}$. The next two blocks of Figure 2, labeled as 'Multimedia and Interactive Content' and 'Implementation of Online Flipped Classroom', are discussed next.

The online delivery will use a flipped classroom approach as defined by the following three main concepts as depicted in Figure 2.

The first concept is to develop engaging and interactive multimedia content. The initial phase consists of developing videos, weekly assessment activities to support frequent testing, assigned readings/homework and weekly laboratory experiments.

To gain experience in developing and delivering online courses, the four instructors (which includes the College of Engineering Chair and the authors) were all involved in creating content for EE110, during the Summer Quarter and Fall Quarter of 2015. Professor Guo was the lead professor integrating the content from other instructors. The planned rollout of the first course was intended to refine the content during these three quarters before delivering the polished version of the first course fully online in 2016.

In 2016, due to workload and resource constraints, the University decided to change its strategy and implement its near-term plan to deliver the graduate engineering programs online since they are relatively easier and have fewer courses to develop than the undergraduate ones. However, the College of Engineering wanted to leverage its success with continous improvement on the delivery of multimedia and interactive content.

The instructors gained valuable skills and insights when creating and testing the content, suitable for online delivery. The engineering content requires integrating it with the University's learning management system (LMS) and its adaptive learning (AL) software ${ }^{7}$ at Chicago. Throughout this development, the integration effort required frequent coordination to ensure a rewarding learning experience for the student. Results of the University's AL software with trigonometry and precalculus courses for the blended learning model appeared in the 2016 ASEE Conference ${ }^{7}$ The College of Engineering intends to use the AL software to provide more practice in solving problems by automating and generating random homework problems for future development of engineering courses. For example, random values of circuit components in various network configurations are generated for each student. Here, students can solve a variety of circuit analysis problems that are different and not repeated for each student using different solution methods. 
The faculty is not only concern with developing multimedia content but one that is interactive. Simply watching videos is mostly a passive activity. The student needs to go beyond stop, pause, rewind and play buttons. During the Fall Quarter of 2016, interactive video was implemented that is becoming a practical and affordable reality. Preliminary survey results show much promise and discussed later in the paper.

It turns out that the use of interactive video will engage the student with the video content.
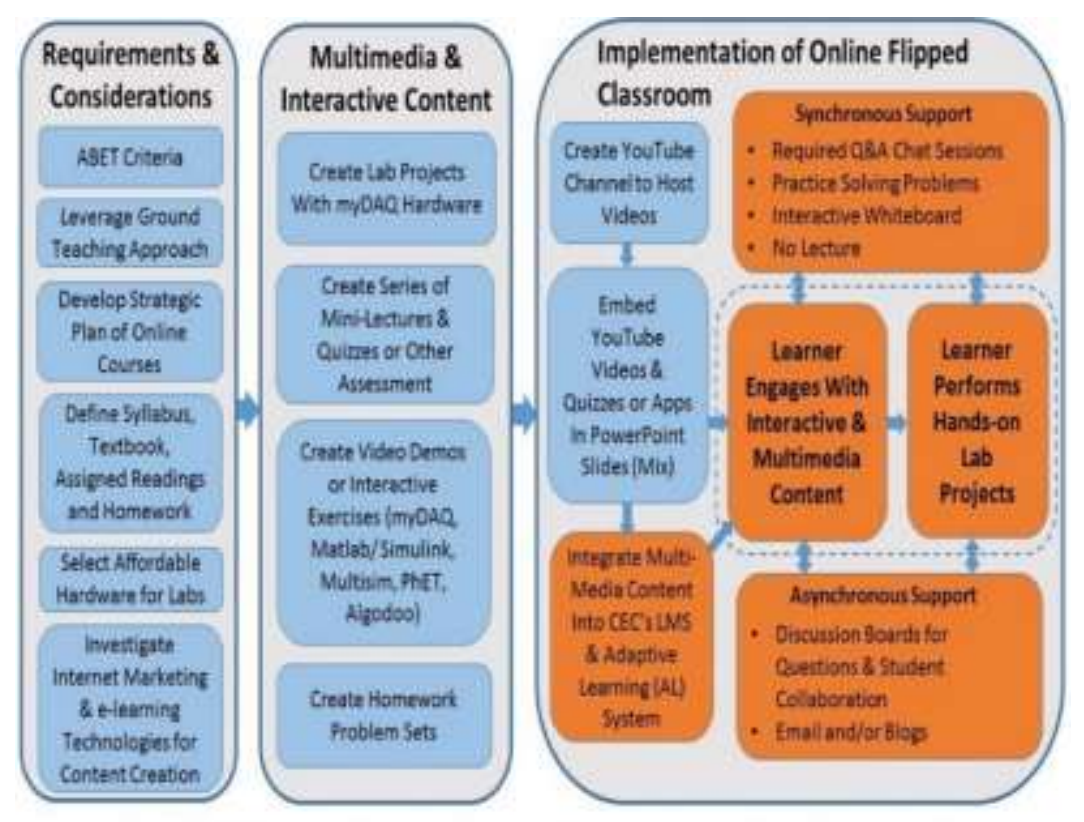

Figure 2. Workflow Delivery of Online Instruction of Engineering Courses

The video has embedded questions and is a key component based on the student comments in Fall Quarter in 2016. The student views the video and after a main topic is discussed in the video, the video automatically pauses when a knowledge check activity is encountered. The pause gives student time to press a knowledge check button to assess their understanding. After the student performs the activity, the e-learner receives immediate feedback and the video continues to play the rest of the video encountering possibly more knowledge checks throughout a short video. The knowledge check keeps the student engage with the material. In essence, interactive video simulates the back and forth conversation between a student and instructor occurring in a traditional face-to-face classroom. Figure 3 depicts before and after a student clicks on a knowledge check button.

It is also important to note the interactions were added using existing YouTube videos without redoing the nine hours and 70-plus videos. Students must view the interactive content outside the classroom while addressing the call-to-action or assignments from the video. These actions must be completed before the online chat session.

The overall goal is to develop effective teaching innovations that would timely help students efficiently learn STEM topics. Developing content suited for online delivery also include: green screen techniques, interactive video and software tools from the internet marketing niche to capture and engage students ${ }^{6}$.

During 2016 Summer Quarter, the set of videos provide a technical foundation made up of a series of short mini-lectures (usually lasting between 5 to 10 minutes for each video) followed by a series of short assessments to verify and validate student understanding using Google Docs.

Video recordings on the use of engineering tools such as Matlab/Simulink, Labview/Multisim, PhET and Algodoo software, can serve as examples to show key concepts. The video instruction can also include demonstrations of real-world applications. For example, in the capstone design 


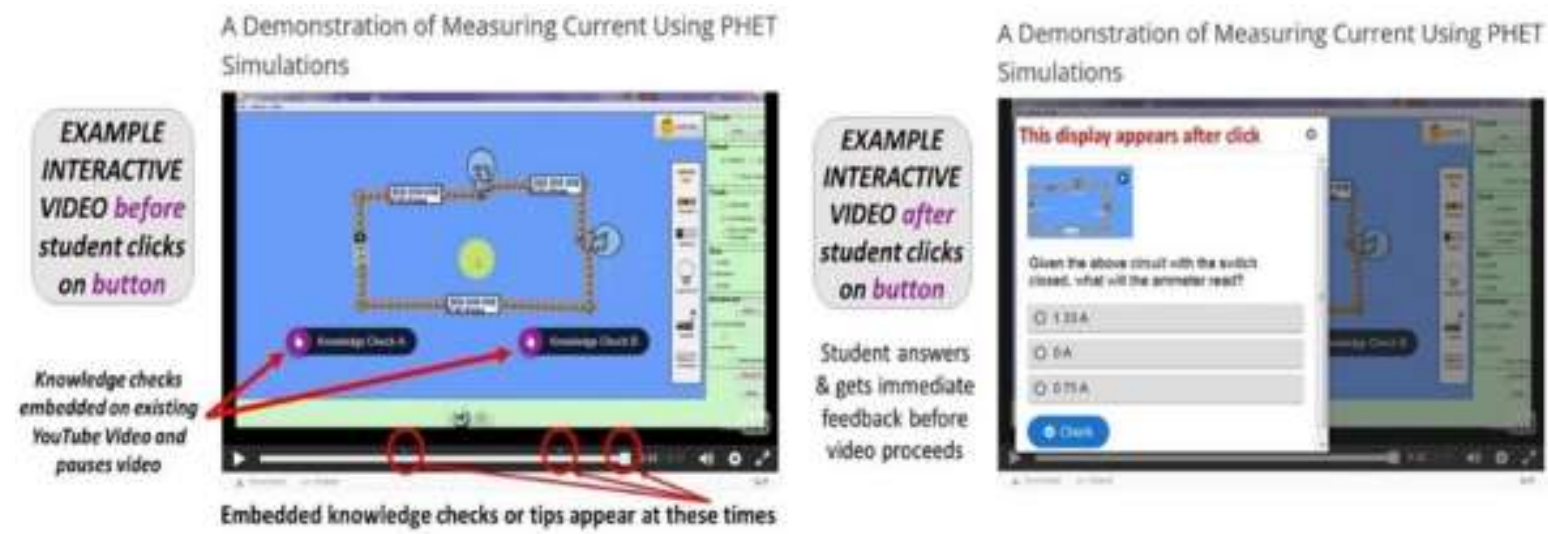

Figure 3. Example of interactive video of screenshots before and after student clicks on knowledge check button

courses and projects, students can use relatively inexpensive microcontrollers such as Arduino, Raspberry PI, and Beaglebone to serve as complementary hardware with the myDAQ from National Instruments. These affordable microcontrollers have been used by past student group projects. Instructors can also use myDAQ and the microcontrollers to demonstrate key concepts found in circuit analysis, electronics and digital courses. To further promote user engagement, any student questions raised from the interactive and multimedia content can be addressed in the online and required interactive chat sessions.

From an online perspective, synchronous delivery means classroom time when the instructor and students are online together (commonly known as a chat or synchronous session). The conduct of the required Q\&A chat sessions are discussed next.

The second concept involves minimal or no lecture material presented during the online chat sessions when students and instructor meet synchronously on a weekly basis, twice a week. The College of Engineering determined that there is very little time to provide a thorough lecture-based material during online sessions. The online chat concept allows more student engagement as a follow-up to the multimedia content presented during the week. The chat sessions are recorded. If students are unable to attend the chat session, then they must view the recording and turn in an assigned project or solve a particular homework problem described during the chat session. Figure 4 depicts the need for synchronous (chat sessions) and asynchronous support (discussion board and email) ${ }^{8,9}$. As depicted in Figure 4, the concept of College of Engineering's online flipped classroom philosophy uses a combination of synchronous chat sessions and asynchronous tools (discussion boards and emails).

Synchronous chat sessions offer self-motivated learners

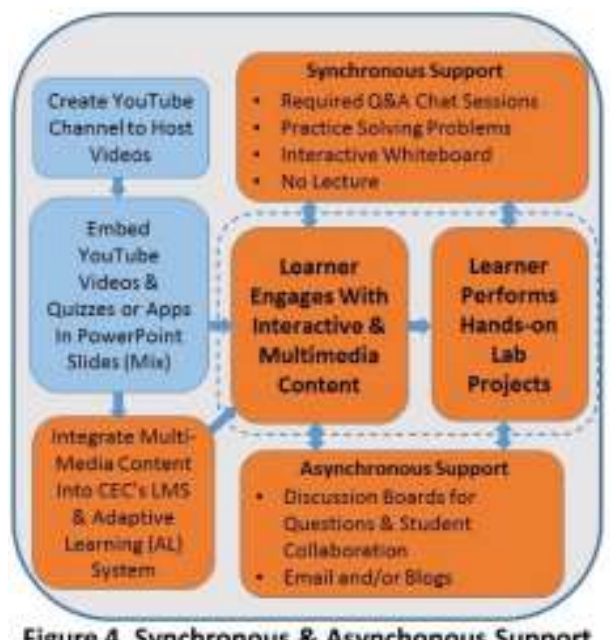
who need more faculty interaction. For those who are unable to attend the synchronous chat sessions, the asynchronous approaches are available for self-motivated students and timeconstrained with the realities of daily life. Although the online content was tested through a 
piloted course with ground (or face-to-face) students, the online teaching pedagogy appears to be reasonable and promising, based on student feedback. Student feedback on the of myDAQ labs is described in more detail by the authors in another paper ${ }^{8}$.

The synchronous chat sessions will also include an interactive whiteboard between the students and instructor. For example, a chat session may involve an instructor who completed step 1 in solving an assigned homework problem on the whiteboard. The instructor can then canvas the audience or select a student by asking: what's the next step toward solving the problem? In addition, pre-assigned homework problems are assigned to students before the weekly chat sessions, prepared to work through their proposed solutions. The primary intent of the chat session is to provide more practice in showing students how to solve more worked-out problems while addressing student questions. Students may ask questions for assigned lab or hands-on activities for that week in another chat session.

These two chat sessions are for addressing student questions based on the weekly online multimedia content, required readings, assigned homework or hands-on laboratory experiments or simulation exercise. The developed multimedia content is consistent with Clark, Nyguen and Sweller focused on efficient learning and effective use of multimedia content ${ }^{4,5}$.

Before the chat session, the instructor can set up and moderate a discussion board where students can submit their questions. Other students can answer these questions as well and earn points toward a leaderboard providing incentives such as reducing the number of assignments that they need to do or earning extra credit points. The chat sessions are primarily student-centered activities based on problem-solving exercises/projects where most of the time is answering student questions. One goal during the chat session is to facilitate and save time for students in solving problems by showing more examples of worked-out problems of assigned homework arising from student questions. Questions on the use of engineering tools described earlier can be addressed here as well.

On a case-by-case basis, if a self-motivated student does not need to attend the chat session and has successfully completed assigned homework before the chat session, then the student gets credit or is excused from attending the session. In summary, this concept requires personalized support for the student than just mere watching of videos. ${ }^{10}$

The final concept consists of weekly hands-on projects to verify and validate the student understanding of concepts, analysis, design and building of their proposed technical solutions. The College of Engineering adopted National Instrument's myDAQ as a learning tool to provide the hands-on experience in several engineering courses, including EE110 which worked well based on student comments. Students need to do projects or lab experiments that are either a software simulation such as PSPICE, Matlab or laboratory experiment using myDAQ hardware with supporting instrumentation software as part of the course. The weekly lab assignments are shown in Figure 3. Student feedback show that they are satisfied with the hands-on teaching approach using myDAQ ${ }^{11,12}$. 
The latest survey results show that the students enjoyed the hands-on lab activities. The successful completion of labs indicate that the multimedia content prepared the student for weekly final quiz assessments and weekly hands-on lab activities. However, based on a student survey, the students expressed concern about how students can collaborate with each other when labs are delivered on-line ${ }^{11,12}$. Based on this concern, students should start chat sessions among themselves with the Learning Management System to document their collaboration or the use of social media can possible serve as

\begin{tabular}{|l|l|}
\hline Week B & Lab Assignments \\
\hline Week01 & Circuits Laboratory Introduction \\
\hline Week03 & Digital I/O Circuits \\
Week04 & Basic Gates Verification \\
Week05 & Digital Simplification \\
\hline Week06 & Ohms Law \\
Week07 & Complex Circuit Analysis \\
Week08 & RC Circuits Multisim Simulation \\
Week09 & Function Generator Assembly \\
Week10 & Function Generator Testing
\end{tabular}

Table 3. Weekly Lab Assignments for Introduction to Engineering (EE110) another approach for collaboration. In place of a written lab or research report for selected projects or lab experiments, each student is tasked to record a 5-to-10 minute video on selected projects or lab experiments whether performed in a group or individual setting for more advance courses.

Laboratory chat sessions can be used to address student questions on the labs as well. Students can submit their lab questions on another discussion board the day before the chat session takes place. The instructor can use the information from the discussion board to prepare for the chat session. Further details about applying this online flip classroom for EE110 can be found in another paper 5 .

On a precautionary note, using the online flipped classroom approach, students are viewing videos, taking frequent assessments, trouble-shooting lab experiments and reading course content on their own time outside the chat sessions. Consequently, the instructor needs to be careful of the student workload when assigning homework. The intention of the synchronous chat sessions, is to perform several worked-out homework problems and address student questions about the assigned homework, laboratory experiments or other student-centered activities as well as any questions arising from the multimedia content.

College of Engineering's online teaching philosophy and implementation will continue to evolve as the engineering faculty gains more experience in delivering courses online. Hopefully, the above and comprehensive discussion of how to deliver an online flipped classroom provided insights on the various issues to consider.

\section{Lessons Learned and Guidelines}

The major considerations and lessons learned when integrating the three concepts are that it's resource intensive, namely:

- Requires extensive time to build quality interactive and multimedia content

- Videos must be short, usually lasting, 5 to 10 minutes, followed with short assessment questions...frequent testing is a must

- Videos are most effective by embedding questions throughout the video to be interactive and engaging.

- Requires learning new skills to produce engaging videos or multimedia content 
- Variety of video types and more engaging videos may be necessary requiring use of green-screen techniques, character animation, gaming techniques, kinetic text and whiteboard video in motivating students to complete a four-to-five year engineering program

- Requires learning new software such as Camtasia for video screen capture and video editing.

- May require learning other content creation tools such as Adobe Products (Photoshop, After Effects, Illustrator, Premier, etc.) for visually appealing content

- Requires a dedicated team with appropriate skill sets to produce quality and engaging online content and design instruction.

- Multimedia or video repositories, real-time and interactive whiteboards and collaborative tools are needed to support the online flipped classroom implementation

The engineering faculty will continue to leverage technology for content creation and online active learning. The College of Engineering also intends to find more efficient ways when developing the course material. For example, if time is an issue in developing video content, then a team of instructors could spend their time researching, leveraging and curating other videos found on YouTube or video repositories.

However, some of the top engineering schools, have posted some of their traditional 45-minute or one hour lectures on YouTube. Selecting and viewing these videos will take time for both instructors and students. Some portions of an hour-long YouTube video developed by other content providers may not be relevant for the course. For the first course, the College of Engineering chose to develop their own content to suit its online needs of instruction. Finding video players to start and stop at the appropriate place would be helpful when curating content from other sources.

Because studying engineering is very challenging for most students, especially when learning the technical content online, the delivery of the course needs to reward self-motivated students with quality content and instruction to keep students engaged in the learning process throughout the engineering program. Taking a long-term strategic view, eventually all engineering courses will be delivered online while ground campuses are for those in the local community who prefer some face-to-face instruction.

In summary, the full-time engineering faculty gained valuable insight in developing multimedia content appropriate for online delivery for the first course. The next section describes past experiences on developing and generating course content suitable for online delivery. Links to YouTube videos created by the engineering faculty with hyperlinked text or images serve as examples in an attempt to provide a more interactive learning experience for the student.

\section{Online Course Delivery Stages and Implementation of Online Delivery Flipped Classroom}

To ensure the quality of the course, the transition from face to face instruction of EE110 to the online delivery of instruction, the department followed several stages as shown in Table 4.

During 2016, due to workload and resource constraints, the University decided to change its strategy and implement its near-term plan to deliver the graduate engineering programs online 
since they are relatively easier and have fewer courses to develop than the undergraduate ones. Delivery of the fully online flipped classroom approach is planned either for the 2017 Spring or Summer Quarter. During this phase, current collaboration tools or innovative use of social media for students will be assessed.

\section{Pilot Stage (Winter 2016) and Focus Meeting Notes}

Initial testing of the pilot course was conducted in 2016 Winter Quarter (Jan-Mar 2016). In the pilot stage, the online teaching environment had been simulated. Students still met five hours per week in class. But in the pilot class, there was no lecture. Students need to go to University online portal and figure out the work they need to complete for the weekly assignments. Students watch videos and do problems that followed each video. For lab exercises and experiments, students need to follow the lab manual, watch the video and review PowerPoint notes of the lab in order to complete the assigned labs. Chat sessions, simulated in the physical classroom, are used to discuss concerns and questions students may have about the assigned engineering problems and another hour is dedicated to answer questions about the lab.

The pilot class simulated the online teaching at some level since there were some significant differences between the pilot class and the 'real' fully online class. In essence, the online multimedia content and its delivery are being tested for both online and 'face-to-face' instruction. However, in this pilot program, instructor still had opportunities to see students set up circuits and can help students debug their circuit. Since students still came to class, they knew each other well, and always helped each other in understanding the engineering concepts and solving problems. For online delivery, students will need to collaborate, possibly through their own chat session or discussion boards to post questions where other students help each other moderated by the instructor. The online chat session and discussion board are planned sometime in 2017. The chat sessions serve as an important component to the online flipped classroom.

During the 2016 Winter Quarter, the College of Engineering held a Pilot Focus meeting that served as an end-of-course feedback in March. Face-to-face student group interviews about the effectiveness of the piloted course was discussed. The course instructor, was not present during the group interview to promote more honest feedback and a less threatening environment. The interview was conducted by the University Engineering Dean and College of Engineering Chair. 
Table 5 are meeting notes summarizing the results from student comments. In general, the overall content and instructional delivery was well received. The content was further refined and developed during the quarter correcting minor errors identified by student feedback.

Several months before the focus meeting, one adjunct professor who taught the introductory course (Fall 2015) and quality-checked the course material reinforced comment 3 of Table 1. The adjunct approached Professor Santiago saying that student feedback on the videos and course content were very good and much appreciated by the students.

\section{STUDENT COMMENTS, WINTER 2016}

1. Student consensus that errors were few but one student found it distracting

2. myOAQ-based equipment is very effective for the lob experiments. There were some issues dealing with insufficient drive current from the internal power supply in myDAQ. There is further need for an external multi-meter to complement the internal one so that voltage and current may be measured simultaneously. One student noted that a distracting lag between his commanding a function and the realization of that command.

3. Videos and slide sets are well done and useful. There is a good balance between poper and online content.

4. The problem assignments were well done and useful

5. One student said that the course is very intense. Snow days should not be allowed. You fall behind.

6. They wondered if online labs would be effective as those in class live and in person. There is a lot of person-to-person interaction in solving problems with the labs. The department chair noted if students attempt the labs ahead of time and bring their issues to the chats, it should work well.

7. In response to one of the question as to whether they believed there might be a blas in industry against engineers who obtained their degrees online, the students opined that there should not be but probably is. But they also said they are not yet engineers, do not work in those circles, and therefore do not know.

Table 5. Pilot Focus Meeting Notes Summarizing Student Feedback On the Piloted Course, Introduction to Engineering during First Pilot, 2016 Winter Quarter

\section{Student Learning Outcome Results from 2016 Winter Quarter}

Eleven students registered for the piloted course at the beginning of 2016 Winter quarter. One student dropped class in the middle of the quarter. The histogram of students' final grades of the ten remaining students in the pilot course and the grades from previous face-to-face course (Fall 2014) taught by the same instructor is shown in Figure 5.

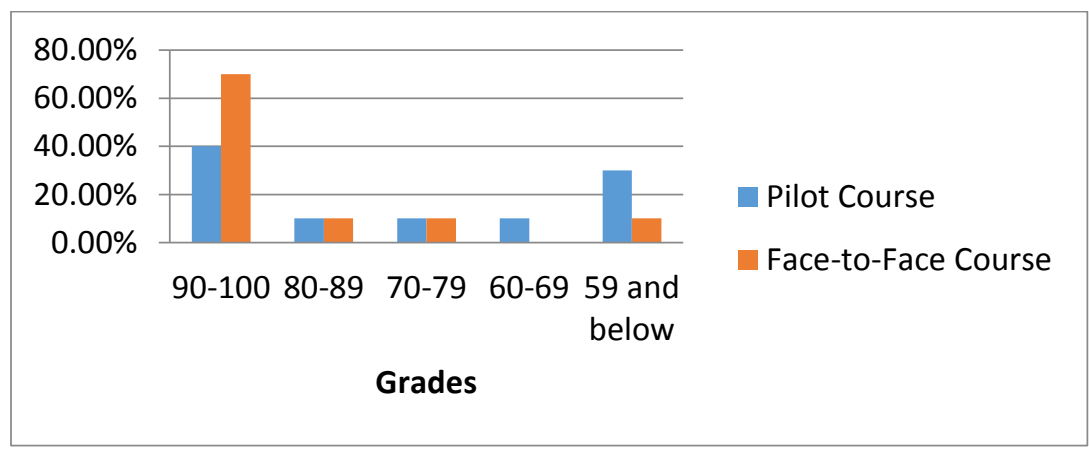

Figure 5. Histograms of Pilot and Face-to-Face Course Grades

From the histograms in Figure 5, the face-to-face students have higher grades than the piloted course. Figure 6 shows the attendance histograms of the Pilot and Face-to-Face course. After comparing the grades of Figure 5 with attendance rates of Figure 6, correlation between grades and attendance rate was found. The three students failed the pilot course attended only $61.9 \%$, $52.4 \%$, and $19.1 \%$ of all class hours and most of the assignments were not completed and 
submitted. All the students in the face-to-face course attended $68 \%$ or more of all class hours. For the students who missed class during the piloted version implies numerous chats session were missed during class. These results from the piloted course appear to show that chat sessions will become a very important component for online delivery.

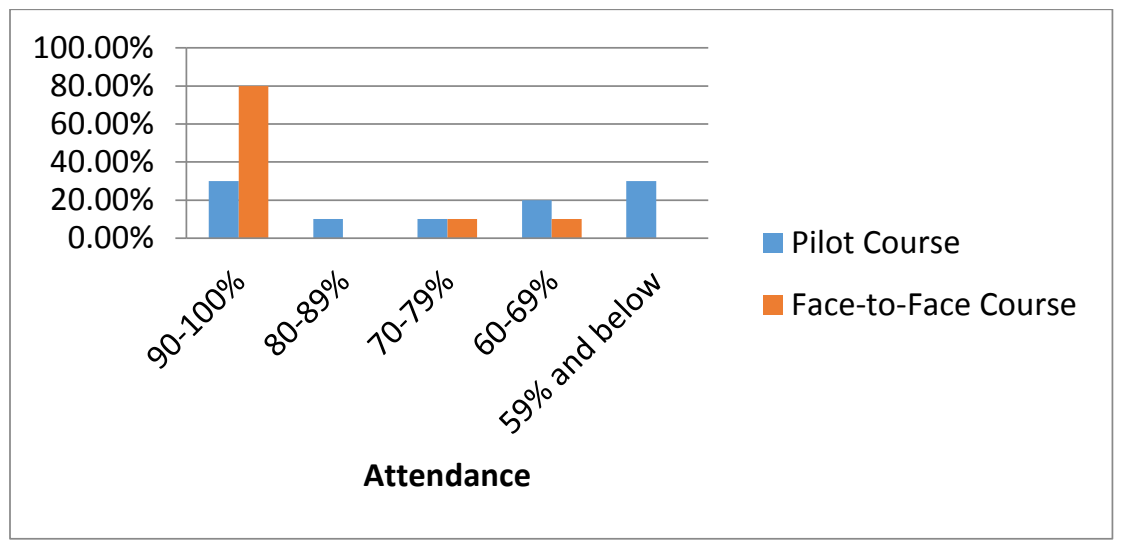

Figure 6. Histograms of Pilot and Face-to-Face Course Attendance Rates

\section{Further Student Responses and Feedback about the Pilot EE110 Course (2016 Winter Quarter)}

One assignment in Week 11 includes a section: "Please provide 2-3 paragraphs that answer the following questions:

- What did I not expect in this course, and was pleasantly surprised to learn/receive?

- What did I expect in this course, and was provided new direction?

- What did I find in the course that was the most challenging?

- What did I find out that I can use to improve in the next course?'

Six out of ten students submitted this assignment, and answered the question. Students' comments about this section are listed in Table 6 below. Based on the students' comments in this assignment; we can see that five out of six students feel the course met their expectation, and they were happy about what they learned from this course. Student \#6 had lower expectations, and he did not like the flipped classroom method, and still hope to use the traditional lab equipment. Students also pointed out that the typos and errors existing in the course material were distracting, and fixed during the next two quarters.

Overall, most students were happy with the multi-media course content and laboratory experiments. However, there will be students who are more comfortable with the traditional face-to-face instruction than with the flipped classroom approach, either delivered on ground or online instruction. The created multimedia content and its method for online delivery appears to prepare the students for the weekly lab assignments.

The left column shows the grade distribution, average percentage grade for the class with and without students who received an F, instructor, and delivery method. Instructor 1 (one of the authors) taught all of the flipped classrooms to simulate the online environment as well as one 


\begin{tabular}{|c|c|}
\hline Student \#1 & $\begin{array}{l}\text { "In this class I got a better understanding of many electronic theories then what I have gotten in classes before this one. I } \\
\text { believe that I should have taken this class before some of the classes like Digital Design } 1 \text { and Circuits } 1 \text {. If I had taken } \\
\text { this class, I do not think that I would have struggled as much in the other classes. What I have learned in this class gave } \\
\text { me a better understanding of logic gates, circuit design, and testing circuits. I have realized in this class that I really like } \\
\text { putting the function generator together and seeing that it works. I now know that I need to improve on my soldering } \\
\text { skills. To me that was the best part of the class. } \\
\text { For me the most challenging part of the class was doing Boolean Algebra and soldering the function generator. Once the } \\
\text { labs get updated for MyDAQ I think this class will be great. I think everyone in the class should have to buy one to be } \\
\text { able to do homework and labs. Sometimes work interferes with my school schedule or if you get sick you can still keep } \\
\text { up with the labs from home. Overall I believe this class is very informational I learned a lot and now I have a better } \\
\text { understanding of circuits." }\end{array}$ \\
\hline Student \#2 & $\begin{array}{l}\text { "To be perfectly honest, I already knew most of the material in this class. However, working on only analog equipment } \\
\text { in the past, the material on digital circuits and Boolean algebra was new. I enjoyed this portion of the class and learned a } \\
\text { lot. I look forward to learning more in this area in future courses." }\end{array}$ \\
\hline Student \#3 & $\begin{array}{l}\text { "This was a great course; I would have to say since we actually learned about Circuits and were able to build them in } \\
\text { labs. This is very helpful since I took a class prior to this and I was somewhat lost. I think if I had taken this course first I } \\
\text { would have had a better grasp on the topic. Along with the fact that I took a higher level course the Boolean algebra is } \\
\text { something that I did expect to learn in this class. The teacher did a great job of showing little tricks in order to simplify } \\
\text { circuits. Through the entire course I found only one thing to be challenging and that was definitely the Boolean algebra. } \\
\text { The short cuts and things that we were taught were very helpful but it was definitely a very challenging topic. Finally the } \\
\text { one thing that I did learn that I can and will use in future courses are how to trouble shoot a circuit that isn't working } \\
\text { properly. } \\
\text { Overall, I feel that this is a great class to have prior to any other courses in order to get a solid foundation and } \\
\text { understanding of what's going on now and in the future." }\end{array}$ \\
\hline Student \#4 & $\begin{array}{l}\text { "When I started this course I didn't expect lower level math to be involved. I was surprised to learn that I was able to } \\
\text { take to Ohm's Law very well as it became a staple for the rest of the term. I also didn't expect that simulations would } \\
\text { play a major role to understand the basics of engineering. I was surprised to find out how well the simulations explained } \\
\text { the validated things like electric fields. I expected out of this course was for it to be somewhat difficult to complete if I } \\
\text { wasn't able to show up to every class. } \\
\text { What I found to be the most challenging in the course was the transition to online which had it bugs. I would assume that } \\
\text { since we were the first class tested under these conditions that the next time around it won't be half in class and half } \\
\text { online. I would say in order to be successful without any hiccups next term the issues like not being able to upload } \\
\text { assignments should be fixed. I would also say that you would also need to just proofread all of the assignments to ensure } \\
\text { that different values aren't referred to like it initially asking for a } 5 \text { ohm cap and at the very bottom of the paper saying } \\
10 \text { ohms. All in all I really did enjoy this class and felt it would be a great step toward someone that is going to work in } \\
\text { the engineering field. " }\end{array}$ \\
\hline Student \#5 & $\begin{array}{l}\text { "I was very happy to have this class as an introductory class into engineering. It shows that there is a lot to learn yet } \\
\text { achievable with enough studying. One thing that I was pleasantly surprised was the building of the signal generator. I } \\
\text { really like how it was hands on and with a few short weeks of class you understood what all the components do as you } \\
\text { then solder them into place on the signal generator. I expected to have a brief understanding of the components prior to } \\
\text { the class but was surprised to learn how in depth we got with them. } \\
\text { I found that the most challenging aspect was the application process once all the information is given then applying } \\
\text { that to the lab. Sometimes it was easy but me being a complete amateur at building on the bread board it was one thing } \\
\text { to learn about it but then completely different once given the bread board to test it. To improve in my next course I plan } \\
\text { on using my brief understanding of the how the bread board works and to always test or model you circuits before } \\
\text { applying them. " }\end{array}$ \\
\hline Student \#6 & $\begin{array}{l}\text { "I really had higher expectations for this course than what I got out of it. I expected in depth lectures and knowledge on } \\
\text { basic electronics but what I got were recorded videos that did not fully explain the concepts and labs I was tasked to } \\
\text { complete without prior guidance as to what we were testing. I expected that test equipment such as multi-meters and } \\
\text { oscilloscopes would be introduced, operations explained, and then had their functions demonstrated so that we could } \\
\text { continue to build upon these tools through our electronics careers. } \\
\text { The challenges for me were interpreting the labs especially when a couple of them had unclear objectives of what we } \\
\text { were meant to accomplish. There were also errors in the labs which suggest that they had not been tested. In our first lab } \\
\text { the wires in the photos were in the incorrect positions of the board, yet if this lab had been constructed and tested... } \\
\text { shouldn't it have easily been identified that the wires were wrong before the photos were taken because the LEDs would } \\
\text { have failed to light." }\end{array}$ \\
\hline
\end{tabular}

Table 6. Student feedback for 2016 Winter Quarter 
ground (traditional face-to-face) class for comparison. Since full-time faculty were creating the online multimedia and interactive content for EE110 during 2015, several instructors taught the ground courses shown in the last three columns. The percentage grades from the last three columns serve as a comparison with the flipped classroom.

\section{Summary of Student Outcomes from Course Continuous Improvement from Winter 2016} to Fall 2016

Table 7 shows the outcome results for the piloted flipped classroom when compared to the ground class for EE110,

As found in the 2016 Winter Quarter survey, mentioned earlier, the students who received Fs resulted from lack of attendance from simulations of chat sessions and lack of submitted work from the students. The authors further investigated the increase in the number of students receiving Fs. Table 8 lists the attendance and grades for students who received an F.

\begin{tabular}{|c|c|c|c|c|c|c|c|}
\hline & Fall2014 & Win2016 & Sum2016 & Fall2016 & Fall2014 & Spr2015 & Fall2015 \\
\hline A & 5 & 3 & 1 & 3 & 1 & 2 & 3 \\
\hline B & 2 & 1 & 2 & 1 & 4 & 2 & 5 \\
\hline C & 1 & 1 & 1 & 1 & 4 & 1 & \\
\hline D & & 1 & 1 & & & & \\
\hline $\mathbf{F}$ & 1 & 3 & 2 & 2 & & & \\
\hline W/o $F$ & 90.6 & 85.5 & 83.0 & 88.8 & 82.7 & 88.1 & 87.7 \\
\hline$w / F$ & 85.2 & 66.7 & 67.0 & 70.7 & & & \\
\hline Instructor & 1 & 1 & 1 & 1 & 2 & 3 & 4 \\
\hline DEUVERY & Ground & Flip & Flip & Flip & Ground & Ground & Ground \\
\hline
\end{tabular}

As shown in Table 8, the students who received an $\mathrm{F}$ had numerous assignments that were not submitted and received a grade of 0 points. It was observed that any assignments that were submitted were mostly from hands-on experiments who had lab partners. Another explanation for the number of Fs as found in 2016 Winter Quarter Survey was that the students did not like the flipped classroom approach and were more comfortable with the traditional face-to-face meeting. The flipped classroom approach requires the student to take on more responsibility of viewing the multi-media content and homework, taking the frequent assessment activities and performing hands-on experiments. This approach may be too much for these students to adapt who are more comfortable with the traditional face-to-face instruction. This situation echoes an idiom: "You can lead a horse to water, but you can't make it drink." 
When removing students with Fgrades from the average percentage grade, the results, highlighted in yellow in Table 7 , show that the flipped classroom approach was effective, especially improving the delivery with interactive video during the 2017 Fall Quarter. The results from the 2016 Fall Quarter are comparable with the 2014 Fall Quarter results. The intent here is not to show which approach is better but to see if the outcomes can be achieved with the flipped

\begin{tabular}{|c|c|l|}
\hline Attendance & \% Grade & \multicolumn{1}{c|}{ Comments } \\
\hline 20.0 & 7.6 & lack of attendance \\
\hline 47.6 & 12.4 & lack of attendance and large number of assignment \\
\hline 50.0 & 37.0 & large number of assignments receiving a grade of O points \\
\hline 60.0 & 23.7 & large number of assignments receiving a grade of Opoints \\
\hline 70.0 & 34.1 & large number of assignments receiving a grade of Opoints \\
\hline 71.4 & 38.6 & large number of assignments receiving a grade of Opoints \\
\hline 80.0 & 36.1 & large number of assignments receiving a grade of Opoints \\
\hline
\end{tabular}

Table 8. Attendance \& percentage grade from students who received an $F$ grade. classroom instruction for online delivery. Students who enroll in an online program may be more conducive to an online flipped classroom approach.

Based on student feedback who have not received an F-grade, the multimedia and interactive content are satisfactory. The delivery using either Google Docs or interactive video are discussed next.

\section{Fall Quarter Results - Using Google Docs and Interactive Video}

The author created a website using a WordPress platform (a content management system) to test the effectiveness of multimedia content with interactive video.

During Fall 2016, EE110 students have seen videos with and without interactions. The results of the four questions are shown in Table 9. Overall, the results show the teaching approach was effective for EE110, especially the interactive video. The general course survey is also presented in another paper $^{13}$. In 2016 Fall Quarter, the students enjoyed the course and hands-on activities along with the associated challenges, especially the soldering tasks. The

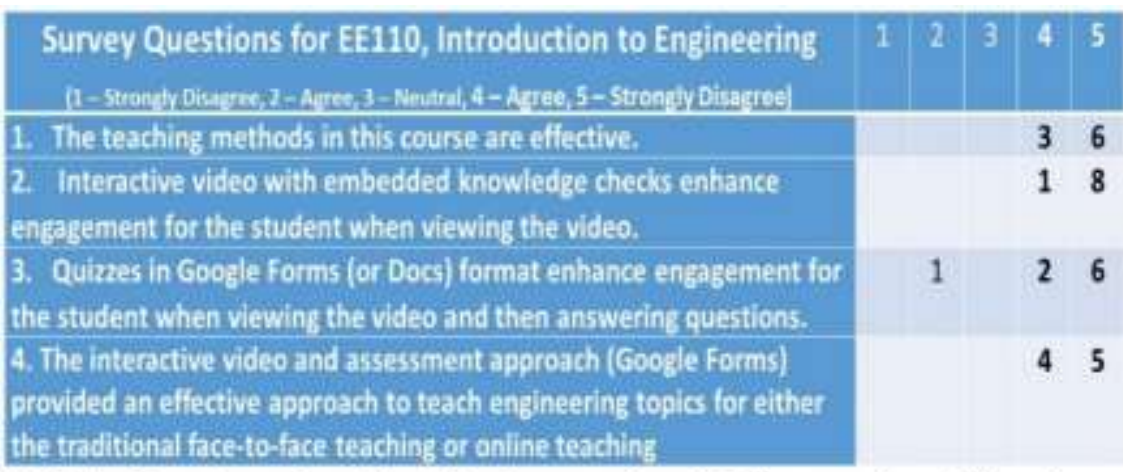

Table 9. Questions about Teaching Approach and Delivery using a Flipped Classroom Pedagogy

results show that the instructional design of the course was effective in having students grasp key and challenging concepts needed to pursue other courses in engineering. Using the flippedclassroom approach, the multi-media content prepared the students to perform the weekly handson lab experiments giving them a solid understanding of key concepts.

The survey allows for student comments. Due to the small number of five students in EE 110 who participated in the survey, four additional students from an advance circuit analysis class 
also participated in the survey to get more data and diversity of students. One student had taken a previous EE 110 class without interactive video but with the use of Google docs. Another student is graduating at the end of the quarter. Two other students need two more years to graduate resulting in a total of nine students viewing the interactive videos. Although this survey is a small sample of the teaching approach of the flipped classroom, the student ratings and comments are instructive.

Results with further explanations on the teaching approach are discussed next. However, only two (Questions 2 and 4) of the four questions are discussed due to the length of the paper. Survey results about the teaching effectiveness are shown in Figures 7 and 8. The figures are two of the four questions about the teaching approach. These figures are screenshots from Google Docs.

Question 2: Interactive video with embedded knowledge checks enhance engagement for the student when viewing the video. In Figure 7, the results show the students significantly liked the interactive video feature to promote engagement. One student would like to have more video lectures set up. Although the videos are relatively short (5 to 10 minutes as a goal), one student mind began to wander and get distracted. The author did some research on mind wondering and found this article ${ }^{10}$.

QUESTIONS RESPONSES

2. Interactive video with embedded knowledge checks enhance engagement for the student when viewing the video:

(9 responses)

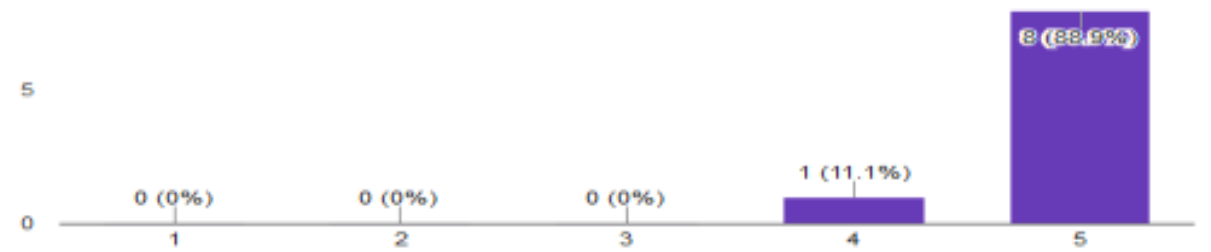

Comments: (3 responses)

More video lectures should be setup like this.

I find that when I watch a long video or a video lecture it is easy for my mind to wander or get distracted. I felt that the knowledge check kept my mind from wandering and helped me to focus on the topio main points of the topic.

The interactive part of the video greatly helps with keeping you engaged with the material.

Figure 7. Interactive Video Engagement

Here's a brief quote on a Harvard study about e-learning when it comes to mind wandering ${ }^{14}$ :

"It was surprising how high the baseline tendency to mind-wander is," Schacter said. "In our experiments, when we asked students if they were mind-wandering, they said yes roughly 40 percent of the time. It's a significant problem... It's not sufficient for a lecture to be short or to break up a lecture as we did in these experiments," Schacter said. "You need to have the testing. 
Just breaking it up and allowing them to do something else, even allowing them to re-study the material, does nothing to cut down on mind-wandering, and does nothing to improve final test performance. The testing is the critical component."

The preliminary results for Fall 2016 survey appears to support frequent testing for each week. This is understandable since most of the students have family and can get easily distracted from social media when viewing the videos at home. By adding interactive features in the video, the knowledge checks appear to keep the learners mind from wandering and to focus on the main topic. The embedded knowledge checks were primarily quizzes with true/false, multiple choice, and fill-in the blanks. Other assessment activities can be used to provide variety in reducing boredom and promote higher-level thinking through reflection exercises. The frequent knowledge assessment questions are consistent with past studies ${ }^{2,4,5}$.

Question 4: The interactive video and assessment approach (Google Forms) provided an effective approach to teaching engineering topics for either the traditional face-to-face teaching or online teaching. This question received the most comments with five. In Figure 8, it appears that the students would be satisfied with the content when the instruction is delivered for either online or traditional face-to-face.

\section{OUESTIOENS RESPONUES}
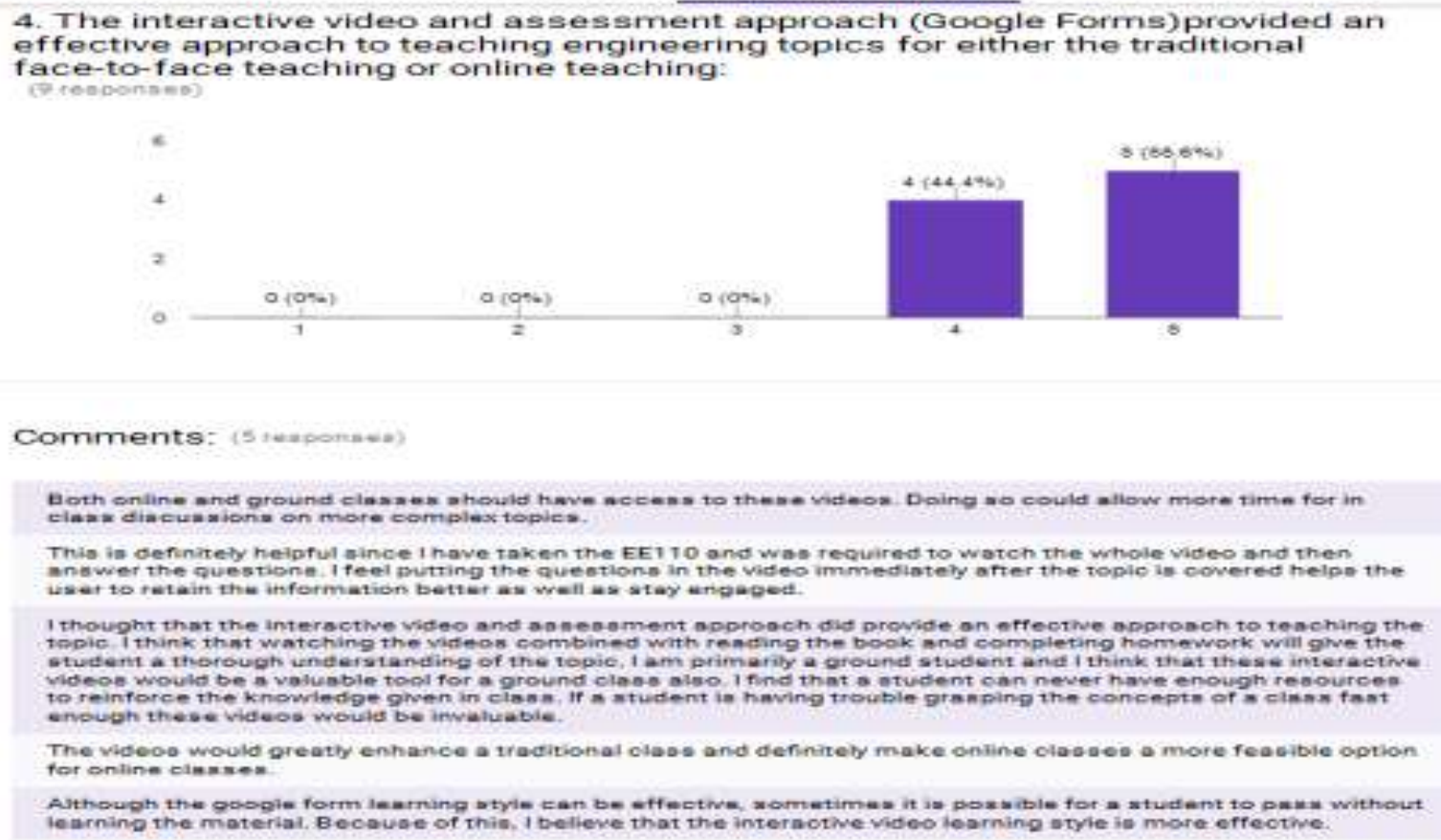

Figure 8. Interactive Video and Google Docs for Online and Traditional Face-to-Face Teaching

Based on the 2016 Fall Quarter and previous survey results, the authors are confident that the multimedia content and teaching approach is effective for either the online or face-to-face traditional instruction. The engineering faculty recognizes the challenge of addressing collaboration among students when conducting their hands-on experiments as well as guiding them during the troubleshooting process. 


\section{Conclusion}

The College of Engineering successfully created interactive and multimedia content to deliver EE110 in support on an Online Flipped Classroom. Base on the student feedback during the last few years, there was a good mix between online video, text content and lab activities. A number of teaching innovations have been presented leveraging technologies to create and deliver interactive and multimedia content. The full-time faculty gained valuable experience and insights producing multimedia content and its delivery using either Google Docs or interactive video. The College of Engineering anticipates the development of future courses will result in shorter timelines as more online courses are implemented in the future. Figure 9 summarizes the approach and experience in leveraging the face-to-face teaching experience during the last few years to transition to the online environment. The College of Engineering used the flipped classroom approach to test the effectiveness of the content and its delivery before making the final transition.

Although the College of Engineering fulltime faculty learned how to develop technical content for online learners, there is still much to learn. There will be students who are more comfortable with the traditional face-to-face teaching. The flipped classroom approach for delivery of either online or face-to-face instruction requires student to take on more
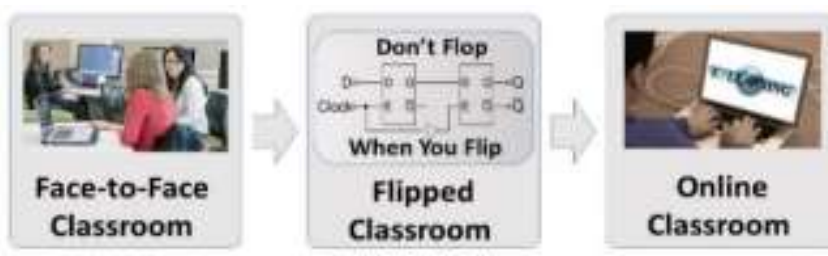

Transitioning from Face-to-Face to Online Teaching

Figure 9. Transitioning from Face-to-Face to Online Teaching Using the Flipped Classroom Approach responsibility with their learning. Learning engineering is already a challenge for most selfmotivated students. So why not serve and reward them with engaging and interactive content that enriches their learning experience during their journey toward an undergraduate engineering program.

\section{References}

1. Gupta, Madhu S, “Teaching Engineering: A Beginner's Guide”, IEEE Press, New York, NY, 1987

2. Carey, Benedict, "How We Learn - The Surprising Truth About When, Where, and Why It Happens", Random House, New York, 2014.

3. Santiago, John, "Circuit Analysis for Dummies”, Wiley, Hoboken, New Jersey, 2013 Santiago, John, Circuit Analysis for Dummies, Wiley, Hoboken, New Jersey, 2013

4. Clark, Ruth, Frank Nguyen and John Sweller, "Efficiency in Learning - Evidence-Based Guidelines to Manage Cognitive Load", Pfeiffer. 2006

5. Clark, Ruth, Richard E. Mayer, "E-Learning and the Science of Instruction - Proven Guidelines for Consumers and Designers of Multimedia Learning”, Third Edition, Pfeiffer, 2011

6. Santiago, John and Jing Guo, "Leveraging Internet Marketing Technologies and Green-Screen Techniques for Developing Engaging STEM and Online Content”, 2016 ASEE Rocky Mountain Section Conference, Cedar City, Utah, September 2016

7. Daines, Jennifer, Tanya Troka, and John Santiago, "Improving Performance in Trigonometry and Pre-Calculus by Incorporating Adaptive Learning Technology into Blended Models on Campus", $123^{\text {rd }}$ Annual ASEE Conference \& Exposition, New Orleans, Louisiana, 2016

8. Higley, Michael, "Advantages Of Using Both Synchronous and Asynchronous Technologies In An Online Learning Environment”, October 15, 2013. Retrieved from https://elearningindustry.com/benefits-ofsynchronous-and-asynchronous-e-learning 
9. Hrastinski, S. (2008). “Asynchronous \& Synchronous e-learning”, EDUCAUSE Quarterly, 31(4), pp. 51-55. Retrieved from http://net.educause.edu/ir/library/pdf/eqm0848.pdf

10. Makice, K., "Flipping the Classroom Requires More Than Video", 2012. Retrieved from: http://www.wired.com/geekdad/2012/04/flipping-the-classroom/

11. Guo, Jing, Kathy Kasley, and John Santiago, "The Challenges of Teaching Engineering Lab Online", 2016 ASEE Rocky Mountain Section Conference, Cedar City, Utah, September 2016

12. Guo, Jing and John Santiago, "Flipped Classroom method in Teaching "Introduction to Engineering" Course online", 2016 ASEE Rocky Mountain Section Conference, September 2016.

13. Santiago, John, Kathy Kasley, Jing Guo, and Pamela Phillips, "Introduction to Engineering Using Google Docs and Interactive Video in Support of an Online Flipped Classroom Approach”, 2017 ASEE Pacific Southwest Conference, Tempe, Arizona, April 2017

14. "Online Learning is Different, Harvard Study", retrieved from https://www.sciencedaily.com/releases/2013/04/130404122240.htm, Harvard University, April 4, 2013 